\title{
A Case Study of Obsessive-Compulsive Disorder: Some Diagnostic Considerations
}

\author{
Jeanette M. Stumbo Zaimes, MD \\ Thomas Jefferson University Hospital
}

Follow this and additional works at: https://jdc.jefferson.edu/jeffjpsychiatry

Part of the Psychiatry Commons

Let us know how access to this document benefits you

\section{Recommended Citation}

Stumbo Zaimes, MD, Jeanette M. (1995) "A Case Study of Obsessive-Compulsive Disorder: Some Diagnostic Considerations," Jefferson Journal of Psychiatry. Vol. 12 : Iss. 2 , Article 5.

DOI: https://doi.org/10.29046/JJP.012.2.011

Available at: https://jdc.jefferson.edu/jeffjpsychiatry/vol12/iss2/5

This Article is brought to you for free and open access by the Jefferson Digital Commons. The Jefferson Digital Commons is a service of Thomas Jefferson University's Center for Teaching and Learning (CTL). The Commons is a showcase for Jefferson books and journals, peer-reviewed scholarly publications, unique historical collections from the University archives, and teaching tools. The Jefferson Digital Commons allows researchers and interested readers anywhere in the world to learn about and keep up to date with Jefferson scholarship. This article has been accepted for inclusion in Jefferson Journal of Psychiatry by an authorized administrator of the Jefferson Digital Commons. For more information, please contact: JeffersonDigitalCommons@jefferson.edu. 


\title{
A Case Study of Obsessive-Compulsive Disorder: Some Diagnostic Considerations
}

\author{
Jeanette M. Stumbo Zaimes, M.D.
}

\begin{abstract}
Obsessive-Compulsive Disorder (OCD) was considered a rare disorder prior to 1984 when the initial results from the Epidemiologic Catchment Area survey demonstrated a substantial prevalence of the disorder (1). Thus there may be many patients today who entered treatment prior to 1984 with undiagnosed OCD. This paper gives the history of one such patient and reviews the current literature on $O C D$ as it pertains to the diagnostic evidence in this case.
\end{abstract}

\section{INTRODUCTION}

Prior to 1984, obsessive-compulsive disorder (OCD) was considered a rare disorder and one difficult to treat (1). In 1984 the Epidemiologic Catchment Area (ECA) initial survey results became available for the first time, and OCD prevalence figures showed that $2.5 \%$ of the population met diagnostic criteria for $\operatorname{OCD}(2,3)$. Final survey results published in 1988 (4) confirmed these earlier reports. In addition, a 6 -month point prevalence of $1.6 \%$ was observed, and a lifetime prevalence of $3.0 \%$ was found. OCD is an illness of secrecy, and frequently the patients present to physicians in specialties other than psychiatry. Another factor contributing to under diagnosis of this disorder is that psychiatrists may fail to ask screening questions that would identify OCD (5). The following case study is an example of a patient with moderately severe OCD who presented to a resident psychiatry clinic ten years prior to being diagnosed with OCD. The patient was compliant with outpatient treatment for the entire time period and was treated for major depressive disorder and borderline personality disorder with medications and supportive psychotherapy. The patient never discussed her OCD symptoms with her doctors but in retrospect had offered many clues that might have allowed a swifter diagnosis and treatment.

\section{CASE HISTORY}

K. was a 42 year old, divorced, Jewish female who worked as a file clerk. She was followed as an outpatient at the same resident clinic since 1984. I first saw her 1993.

Jeanette Zaimes, M.D. is a fourth year resident in the Department of Psychiatry at Thomas Jefferson University Hospital in Philadelphia. 
Her first words to me were a long and anxiety filled account of how she thought that she was getting a vaginal yeast infection and she believed this would ruin her weekend trip with her boyfriend. She was convinced that there had been fecal contamination of her vagina after a recent bowel movement. She described in detail how this could happen. Once this complaint was reviewed, she shifted her attention to negotiating a relationship with me. Her first request was to increase the frequency of her sessions from monthly to weekly. She had discussed this with her previous doctor and they had agreed she might benefit from more frequent sessions given some specific goals for treatment. She wanted to improve her ability to maintain relationships in her life. She noted that she had been very promiscuous over the years, but was currently involved with a boyfriend whom she had seen for the past 3 years. She also felt that she talked too much and made relationships difficult to maintain by driving people away with her nonstop chatter.

\section{PAST PSYCHIATRIC HISTORY}

$\mathrm{K}$. had been seen in the resident outpatient clinic since July of 1984 . Prior to this she had not been in psychiatric treatment. She had never been hospitalized. Her initial complaints were depression and anxiety and she had been placed on an phenelzine and responded well. Her depression was initially thought to be secondary to amphetamine withdrawal, since she had been using diet pills for 10 years. She stated that at first she took them to lose weight, but continued for so long because people at work had noted that she concentrated better and that her job performance had improved. In addition, her past doctors had all commented on her limited ability to change and her neediness, insecurity, low self-esteem, and poor boundaries. In addition, her past doctors had noted her promiscuity and frequent masturbation (4 or 5 times per day). All noted her poor attention span and limited capacity for insight. Neurological testing during her initial evaluation had shown the possibility of non-dominant parietal lobe deficits. Testing was repeated in 1989 and showed "problems in attention, recent visual and verbal memory (with a greater deficit in visual memory), abstract thought, cognitive flexibility, use of mathematical operations, and visual analysis. A possibility of right temporal dysfunction is suggested." IQ testing showed a combined score of 77 on the Adult Weschler IQ test, which indicated borderline mental retardation.

Over the years the patient had been maintained on various antidepressants and antianxiety agents. These included phenelzine, trazadone, desipramine, alprazolam, clonazapam, and hydroxyzine. Currently she was on fluoxetine $20 \mathrm{mg}$ daily and clonazapam $0.5 \mathrm{mg}$ twice a day and $1.0 \mathrm{mg}$ at bedtime. The antidepressants had been effective over the years in treating her depression. She has never used more clonazapam than prescribed and there was no history of abuse of alcohol or street drugs. Also, there was no history of discreet manic episodes and she was never treated with neurolepics. 


\section{PAST MEDICAL HISTORY}

She suffered from gastroesophageal reflux and was maintained symptom free on a combination of ranitidine and omeprazole.

\section{PSYCHOSOCIAL HISTORY}

K. was born and raised in a large city. She had a brother who was 3 years younger. She described her father as morose, withdrawn, and recalled that he has said, "I don't like my children." One of the patient's earliest memories of was being told by him that her "butt was too big." Her father was physically and verbally abusive throughout her childhood. She had always longed for a good relationship with him. K. described her mother as the family martyr and the glue that held the family together. She stated that she was very close to her mother; her mother always listened to her and was always available to talk with her.

K. was a poor student, had difficulty all through school, and described herself as "always disrupting the class by talking or running around." She had a best friend through grade school whom she stated "deserted" her in high school. She had maintained few close friends since then.

K. graduated high school with much difficulty and effort. She dated on group dates but never alone. She remained a virgin until her marriage at 19 years old which lasted less than one year. Her husband left her while she was pregnant with her son. The husband was abusive and had not had a role in their lives since the divorce. After the divorce, K. moved back to her parents' home with her son and remained there until getting her own apartment 3 years ago. Her son is currently 21 years old, recently graduated from college and lives with K.'s parents. K. has worked for the same company in various positions for the past 22 years. She currently works as a file clerk.

\section{FAMILY HISTORY}

K.'s mother had two serious suicide attempts at age 72 and was diagnosed with major depressive disorder with psychotic features and OCD. She also had non-insulin dependent diabetes mellitus and irritable bowel syndrome.

K.'s brother was treated for OCD as an outpatient for the past 20 years and also has Hodgkin's Disease, currently in remission. The brother's diagnosis of OCD was kept secret from K. and did not become available to K.'s doctors until the mother was hospitalized in 1994.

$\mathrm{K}$.'s father is alive and well.

\section{MENTAL STATUS EXAM}

K. was a thin, bleached blond woman who appeared her stated age. She was dressed in skin tight, provocative clothing, costume jewelry earrings that eclipsed her ears and hung to her shoulders, heavy make-up and elaborately styled hair. She had 
difficulty sitting still and fidgeted constantly in her chair. Her body language throughout the interview was sexually provocative. Her speech was rapid, mildly pressured, and she rarely finished a sentence. She described her mood as "anxious." Her affect appeared anxious. Her thought processes showed mild circumstantiality and tangentiality. More significant was her inability to finish a thought as exhibited by her incomplete sentences. Her thought content was focused upon sexual themes, including frequency of masturbation, worry over vaginal cleanliness, and frequency of orgasm. K. denied suicidal or homicidal ideations, auditory or visual hallucinations. Cognitive testing was not formally done.

\section{COURSE OF TREATMENT}

Initial sessions with the patient were spent gathering history and forming a working alliance. Because of the patient's history of an attention deficit that was confirmed by neuropsychological tests, she was started on a trial of methyphenidate. Although she showed a good response by slowing down enough to finish sentences and focus on conversations, she could not tolerate the side effects and refused to continue taking the medication.

The winter of 1993-94 was particularly harsh. The patient missed many sessions because of bad weather. A pattern began to emerge of a consistent increase in the number of phone calls that she made to the office voice mail to cancel a session. This pattern called to mind a discussion in supervision that the patient's frequent masturbation had a compulsive quality to it and to listen for other evidence of obsessions or compulsions. When K. was questioned about her phone messages she stated, "I always repeat calls to make sure my message is received." Since the most recent cancellation generated no less than six phone calls, she was asked why a second call wouldn't be enough "to be sure." She laughed nervously and said, "I always repeat things."

With careful questioning the following behaviors were uncovered. The patient checked all locks and windows repeatedly before retiring. She checked the iron a dozen times before leaving the house. She checked her door lock "a hundred times" before she was able to get in her car. She masturbated each morning before arising because she had a terrible feeling that if she didn't, something bad would happen to her. She masturbated at certain times throughout the day for the same reason. The patient washed her hands frequently. She carried disposable washcloths in her purse "so I can wash as often as I need too." She said people at work laugh at her for washing so much. But she stated, "I can't help it. I've been this way since I was a little girl." When questioned about telling former doctors about this, the patient stated that she had never talked about it with her doctors. She stated that everyone that knew her simply knew that this was the way she was: "It's just me." In fact, she stated, "I didn't think my doctors would care... I've always been this way so it's not something you can change."

Over the next few sessions, it became clear that her arguments with her boyfriend centered on his annoyance with her need to constantly repeat things. This was what she always referred to as "talking too much." In sessions it was observed 
that K.'s anxiety, neediness and poor boundaries arose over issues of misplacing things in her purse and insurance forms that were incorrectly filled out. In fact, when I attempted to correct the insurance forms for her, I had difficulty because of her need to repeat the instructions to me over and over. Then she spent ten minutes checking and rechecking the form against the receipts. She became convinced that she'd done it wrong, her anxiety would increase, and she would get the forms out and check them again. Her need to include me in this checking was so great that she was almost physically on top of my chair.

In the following weeks, sessions focused on educating the patient about OCD. Her dose of fluoxetine was increased to $40 \mathrm{mg}$ a day but discontinued because of severe restlessness and insomnia. She continued to take $20 \mathrm{mg}$ of fluoxetine a day. Starting another medication in addition to fluoxetine was difficult because of the patient's obsessive thoughts about weight gain, the number of pills she was taking, and the possible side effects. Finally, the patient agreed to try adding clomipramine to her medications. The results were dramatic. She felt "more relaxed" and had less anxiety. She's limited many of her checking rituals. She washed her hands less often and she no longer compulsively masturbated. She began to talk, for the first time, about her abusive father. She said, "His behavior was always supposed to be the family secret. I felt so afraid and anxious I didn't dare tell anyone. But now I feel better. I don't care who knows. It's cost my mother too much to stay silent."

At this time the plan is to begin behavioral therapy with the patient in addition to medications and supportive therapy to deal with her difficulties with relationships.

\section{DISCUSSION}

This is a complicated case with multiple diagnoses: borderline mental retardation, attention deficit disorder, borderline personality disorder, a history of major depressive disorder and obsessive compulsive disorder. Given the level of complexity of this case and the patient's own silence about her symptoms, it is not surprising that this patient's OCD remained undiagnosed for so long. However, in reviewing the literature and the case, it is instructive to look at the evidence that might have led to an earlier diagnosis.

First of all, there was the finding of soft neurological deficits. The patient's neuropsychological testing suggested problems with visuospacial functioning and visual memory, as well as attentional difficulties and a low IQ. In the past, her doctors were so impressed with her history of cognitive difficulties that neuropsychological testing was ordered on two separate occasions. Four studies in the recent literature have shown consistent findings of right hemispheric dysfunction, specifically difficulties in visuospatial tasks, associated with OCD $(6,7,8,9)$.

The patient also had a history of chronic dieting, and although extremely thin, she continued to be obsessed with not gaining a single pound. This was a patient who took diet pills for 10 years and whose earliest memories involved her father's disapproval of her body habitus. Eating disorders are viewed by some clinicians as a form of OCD. Jenike (10) states that besides exhibiting a morbid obsession with food and thinness, many patients with anorexia and bulimia also exhibit frank OCD. 
Swedo and Rapoport (11) also note an increased incidence of eating disorders in children and adolescents with OCD.

Perhaps the most obvious clue was the patient's presenting complaint in her first session. She began, before the door had even closed, to describe an intense fear of vaginal contamination by feces. The patient stated that she had washed and checked the vulvar area several times but was still convinced that feces had entered her vagina. My initial impression was that she was exhibiting the poor boundaries often observed in borderline personality disorder. While this was no doubt true, the underlying obsessional content pointed directly to OCD and should have generated a list of screening questions for OCD. This underscores the need to be vigilant for diagnostic clues and to perform one's own diagnostic assessment when assuming the treatment of any patient.

While the literature makes it clear that OCD runs in families (12), the patient was unaware of the illness in her family until after her diagnosis was made. It would have been helpful to know this information from the beginning as it should immediately raise a suspicion of OCD in a patient presenting with complaints of depression and anxiety.

Finally, her diagnosis of borderline personality disorder made it easier to pass off her observable behavior in the office as further evidence of her character structure. The diagnosis of borderline personality disorder was clear. She used the defense of splitting as evidenced by her descriptions of her fights with her boyfriend. He was either "wonderful" or a "complete bastard." Her relationships were chaotic and unstable. She had no close friends outside of her family. She exhibited affective instability, marked disturbance of body image and impulsive behaviors, i.e. her promiscuity and masturbatory activity. However, it was difficult to discern whether her symptoms were truly characterological or due instead to her underlying OCD and related anxiety. For instance, the instability in her relationships was, in part, the result of her OCD, since once she began to obsess on something, she repeated herself so much that she frequently drove others into a rage.

A study by Ricciardi, et al. (13), investigated DSM-III-R Axis II diagnoses following treatment for OCD. Over half of the patients in the study no longer met DSM-III-R criteria for personality disorders after behavioral and/or pharmacological treatment of their OCD. The authors conclude that this raises questions about the validity of an Axis II diagnosis in the face of OCD. One might also begin to wonder how many patients with personality disorders have undiagnosed OCD?

Rasmussen and Eisen (1) found a very high comorbidity of other Axis I diagnoses in patients with OCD. Thirty-one percent of patients studied were also diagnosed with major depression, and anxiety disorders accounted for twenty-four percent. Other coexisting disorders included eating disorders, alcohol abuse and dependence, and Tourette's syndrome. Baer, et al. (14) investigated the comorbidity of Axis II disorders in patients with OCD and found that 52 percent met the criteria for at least one personality disorder with mixed, dependent and histrionic being the most common disorders diagnosed.

Given the frequency of comorbidity in patients with OCD, it would be wise to include screening questions in every psychiatric evaluation. These need not be 
elaborate. Questions about checking, washing, and intrusive, unwanted thoughts can be simple and direct. In eliciting a family history, specific questions about family members who check repeatedly or wash frequently should be included. Simply asking if any family member has OCD may not elicit the information, since family members may also be undiagnosed.

In summary, this case represents a complicated diagnostic puzzle. Her past physicians did not have the information we do today to unravel the tangled skeins of symptoms. It is important to be alert for the possibility that this patient's story is not an uncommon one.

\section{REFERENCES}

1. Rasmussen SA, Eisen JL: Epidemiology of obsessive compulsive disorder. J. Clin. Psychiatry 1990; 51(suppl 2):10-13

2. Meyers JK, Weissman MM, Tischler GL, et al: Six-month prevalence of psychiatric disorders in three sites. Arch. Gen. Psychiatry 1984; 41:959-971

3. Robin LN, Helzer JE, Weissman MM, et al: Lifetime prevalence of specific psychiatric disorders in three sites. Arch. Gen. Psychiatry 1984; 41:949-959

4. Karno M, Golding JM, Sorenson SB, et al: The epidemiology of obsessive-compulsive disorder in five U.S. communities. Arch. Gen. Psychiatry 1988; 45:1094-1099

5. Rasmussen SA, Eisen JL: The epidemiology and differential diagnosis of obsessive compulsive disorder. J. Clin. Psychiatry 1992; 53(suppl 4):4-10

6. Diamond BM, Borison W, Borison RL: Neuropsychology of obsessive compulsive disorders. In: Forty-Third Annual Convention and Scientific Program, the Society of Biological Psychiatry May 4-8, 1988; Montreal, Canada

7. Hollander E, Schiffman E, Cohen B, River-Stein MA, Rosen W, Gorman JM, Fyer AJ, Papp L, and Leibowitz MR: Signs of central nervous system dysfunction in obsessive-compulsive disorder. Arch. Gen. Psychiatry 1990; 47:27-32

8. Insel T, Donnelly E, Lalakea M, Alterman IS, Murphy DL: Neurological and neuropsychological studies of patients with obsessive-compulsive disorder. Biol. Psychiatry 1983; 18:741-751

9. Rosen WG, Hollander E, Stannick V, Leibowitz MR: Test performance variables in obsessive-compulsive disorder. J. Clin. Exp. Neuropsychol. 1988; 40:73

10. Jenike MA: Illness related to obsessive-compulsive disorder. In: Obsessive-compulsive disorders theory and management. Jenike MA, Baer L, Minichiello WE. Mosby Year Book, St. Louis, Mo. 1990; p. 39-60

11. Swedo SE, Rapoport JL; Phenomenology and differential diagnosis of obsessive-compulsive disorder in children and adolescents. In: Obsessive-compulsive disorder in children and adolescents. Rapoport JL. American Psychiatric Press, Inc. Washington, D.C. 1989; p $18-19$

12. Nemiah JC and Uhde TW: Obsessive-compulsive disorder. In: Comprehensive Textbook of Psychiatry/V. Kaplan HI and Sadock BJ. Williams and Wilkins, Baltimore. 1989; p. 986

13. Ricciardi JN, Baer L, Jenike MA, Fischer SC, Sholtz D, Buttolph ML; Changes in DSM-III-R diagnosis following treatment of obsessive-compulsive disorder. Am. J. Psychiatry 1992; 149:829-831

14. Baer L, Jenike MA, Ricciardi JN, Holland AD, Seymour RJ, Minichiello WE, Buttolph ML: Standardized assessment of personality disorders in obsessive-compulsive disorder. Arch Gen Psychiatry 1990; 47:826-830 